\title{
MCD and MCPL Characterization of Luminescent Si(IV) and P(V) Tritolylcorroles: The Role of Coordination Number
}

\author{
Simone Ghidinelli, Sergio Abbate, Giuseppe Mazzeo, Roberto Paolesse, Giuseppe Pomarico,* \\ and Giovanna Longhi*
}

Cite This: ACS Omega 2021, 6, 26659-26671

Read Online

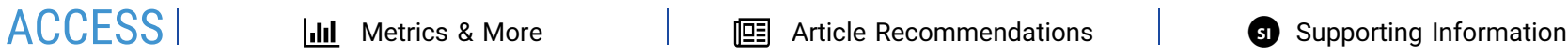

ABSTRACT: Two triarylcorrole complexes, (hydroxy) $[5,10,15-$ tritolylcorrolato]silicon-(TTC) Si(OH) and (dihydroxy) $[5,10,15$ tritolylcorrolato] phosphorous-(TTC) $\mathbf{P}(\mathbf{O H})_{2}$, have been investigated by magnetic circular dichroism (MCD) and magnetic circularly polarized luminescence (MCPL). The spectroscopic investigations have been combined with explicit calculation of MCD response through time-dependent density functional theory (TD-DFT) formalism. This has allowed us to better define the role of molecular orbitals in the transitions associated with the Soret and Q bands. Besides and more importantly, MCD has made it possible to follow the titration process of (TTC) $\mathrm{Si}(\mathrm{OH})$ in dimethyl sulfoxide (DMSO) solution with $\mathrm{NaF}$ and of (TTC) $\mathbf{P}(\mathbf{O H})_{2}$ in dichloromethane solution with alcohols in a complementary and, we dare say, more sensitive way with

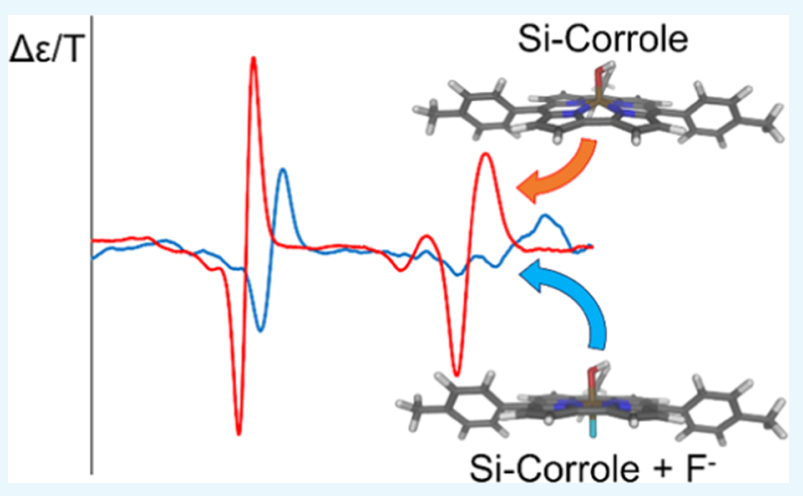
respect to absorption and fluorescence data. Finally, the MCPL spectra and the ancillary TD-DFT calculations have allowed us to characterize the excited state of (TTC)Si(OH).

\section{INTRODUCTION}

The pursuit of a synthetic way to prepare vitamin $B_{12}$ allowed Johnson and Kay to identify for the first time a new member of the porphyrinoid family, ${ }^{1}$ which they named corrole due to its structural similarity with the corrin ring. From a structural point of view, corrole is a contracted porphyrin, missing one meso carbon atom, while the $\mathrm{N}_{4}$ unit of the inner cavity is a tetradentate trianionic chelating system.

It is quite surprising how the small differences between the molecular framework of corrole and porphyrin have a so large effect in terms of chemical properties. Compared to porphyrin, corrole is more electron-rich and undergoes oxidation easily; the inner core is either protonated or deprotonated under mild conditions forming the monocationic or the monoanionic derivatives, and finally, it acts as a trianionic ligand toward metal ions coordinated in the inner core, allowing the stabilization of elements in a formally higher oxidation state than porphyrins. ${ }^{2-4}$ The presence of the electron-rich corrole ligand and metal ion in a high oxidation state favors ligand-tometal charge transfer with the formation of macrocyclic $\pi$ cation radical species, leading to the frequent noninnocent character of corrole as ligand.

The richness of the properties of corrole has favored its exploitation in different fields: as an organic material in chemical sensors ${ }^{6}$ or for energy conversion, ${ }^{7,8}$ in medicine, ${ }^{9,10}$ and as a catalyst. ${ }^{11,12}$

To make it possible to prepare corrole-based organic materials applied in such different areas, it is required to tune the properties of the macrocycle by chemical functionalization of the framework, and consequently, it is first necessary to unveil the effects of those modifications upon the chemical, electrochemical, and photophysical features of corroles.

Among all of the properties of tetrapyrroles, special attention has been directed toward their ability to absorb/emit light and to the effect that coordination of metal ions has on the intensity and/or wavelength of the absorption and emission bands. The greatest benefit by the formation of luminescent metal complexes is obtained when some elements of groups 13-15 are coordinated to the macrocycle core.

Aluminum, ${ }^{13,14}$ gallium, ${ }^{13-16}$ silicon, ${ }^{17,18}$ germanium, ${ }^{19}$ and phosphorous $^{20-23}$ have in common the formation of complexes that stand out for their high molar extinction coefficient (similar to those of porphyrins) and intense emission bands, which make metallo-corrolates interesting dyes for application in different fields.

Received: July 28, 2021

Accepted: September 14, 2021

Published: September 29, 2021

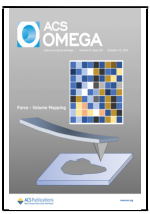


Scheme 1. (TTC) $\mathrm{Si}(\mathrm{OH})$ and (TTC) $\mathrm{P}(\mathrm{OH})_{2}$ (Left: Hexa-Coordinated; Right: Penta-Coordinated) Here Investigated ${ }^{a}$

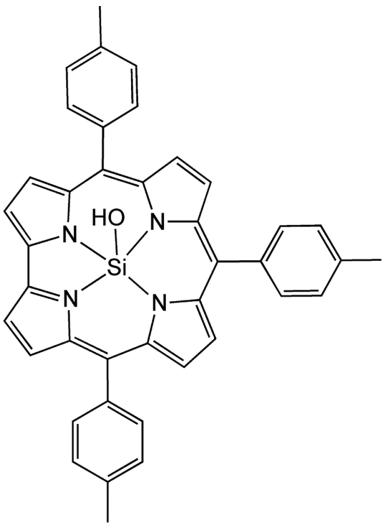

(TTC)Si(OH)

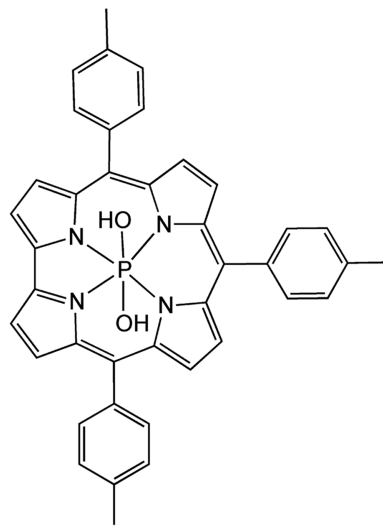

(TTC)P(OH $)_{2}$

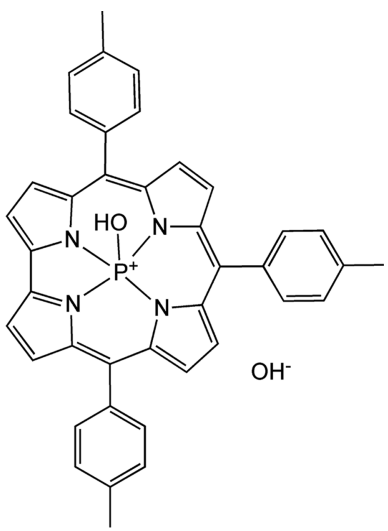

$[(\mathrm{TTC}) \mathrm{P}(\mathrm{OH})]^{+}(\mathrm{OH})^{-}$

${ }^{a}$ Later in the text, we use these abbreviations to generally refer to silicon and phosphorous corrole complexes. Exact number/type of axial ligand is detailed if needed, according to the structures drawn in Schemes 1 and 2 and Figure S3 (see below).
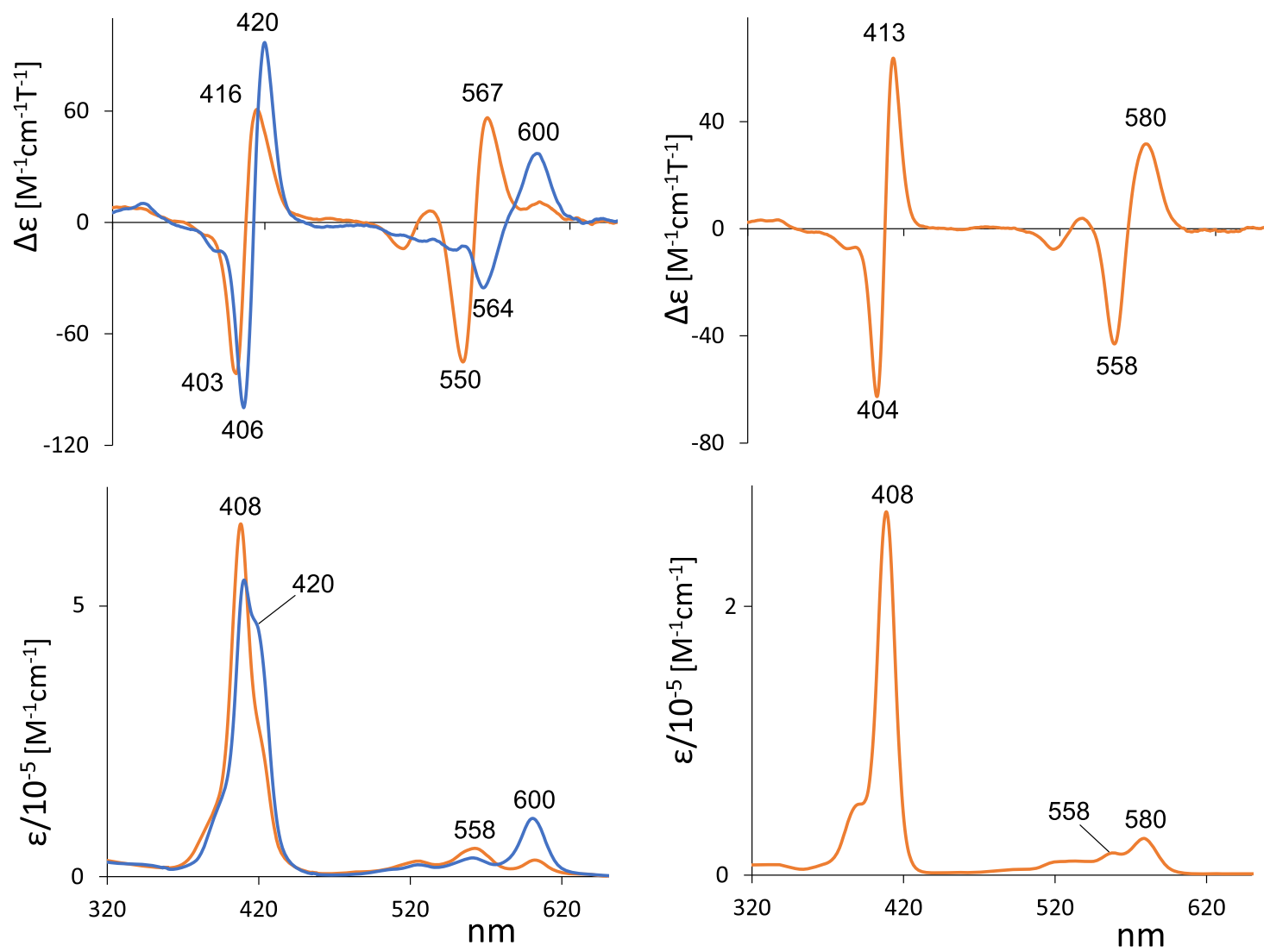

Figure 1. Left: Experimental MCD (top) and UV-vis (bottom) spectra of (TTC) $\mathbf{P}(\mathbf{O H})_{2}$ in $\mathrm{CH}_{2} \mathrm{Cl}_{2}$ (orange) and methanol solutions (blue). Right: Experimental MCD (top) and UV-vis (bottom) spectra of (TTC) $\mathrm{Si}(\mathrm{OH})$ in $\mathrm{CH}_{2} \mathrm{Cl}_{2}$.

Optical spectra of metallocorroles are described with good approximation by Gouterman's ${ }^{24,25}$ four-orbital model; this theory previously developed to explain the electronic spectra of porphyrins accounts well also for corroles. According to this model, electronic transitions originating Soret and Q bands are due to two almost degenerate highest-occupied molecular orbitals (HOMOs) and two lowest-unoccupied molecular orbitals (LUMOs), which are energetically separated from other occupied and unoccupied molecular orbitals.
In spite of the growing interest in the optical properties of corroles, both free base and metal complexes, the number of reports investigating the electronic structures of this class of compounds from theoretical and spectroscopic points of view is limited $^{3}$ if compared with the more amply studied porphyrins. Many studies have been carried out on first-row transition-metal complexes ${ }^{3,4}$ that are nonfluorescent because the central metal originates a low-lying charge transfer state.

To obtain more information about the relationship between electronic structures and optical features of metallo-corrolates, 
Scheme 2. Conversion of Penta-/Hexa-Coordinated Corrole into the Methoxy Derivatives ${ }^{a}$

$(\mathrm{TTC}) \mathrm{P}(\mathrm{OH})_{2}$

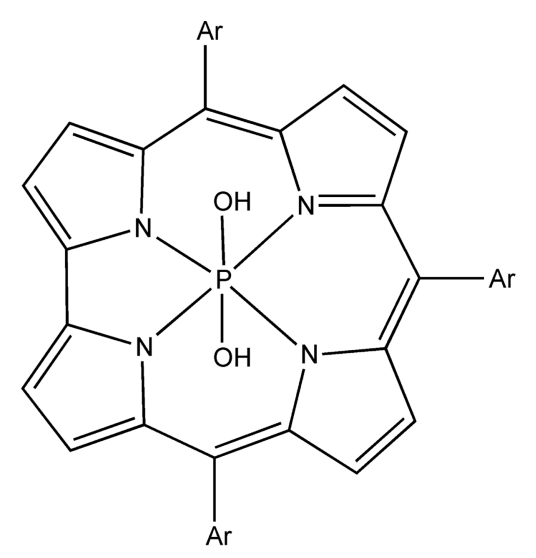

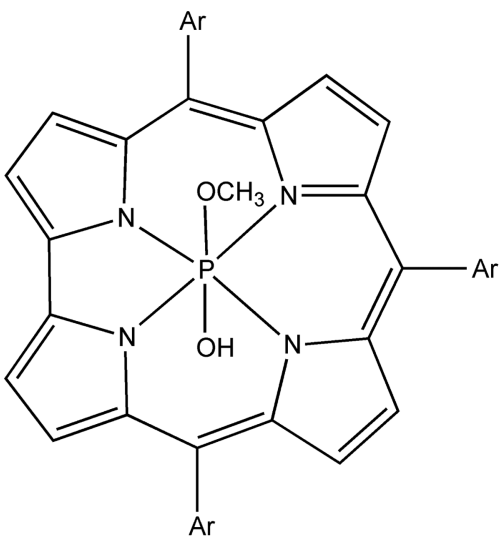

(TTC)P(OH) $\left(\mathrm{OCH}_{3}\right)$
$[(\mathrm{TTC}) \mathrm{P}(\mathrm{OH})]^{+}(\mathrm{OH})^{-}$<smiles></smiles>

$+\mathrm{CH}_{3} \mathrm{OH}$

$+$

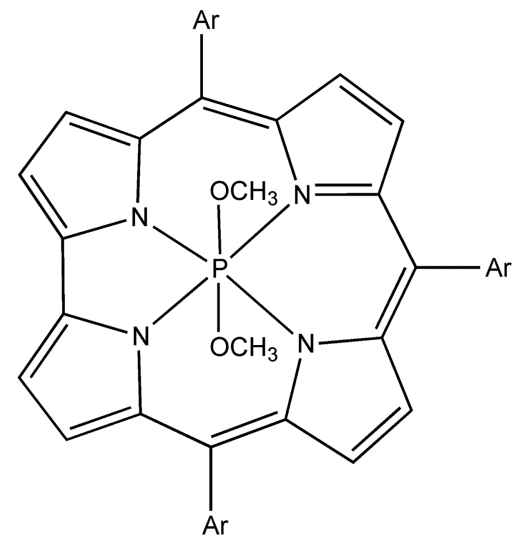

(TTC)P( $\left(\mathrm{OCH}_{3}\right)_{2}$

$\mathrm{Ar}=$ tolyl

${ }^{a}$ Number of $\mathrm{CH}_{3} \mathrm{O}-$ groups is a function of methanol equivalents.

we focused our attention on Si and P triarylcorrolates, chosen for their intriguing photophysical properties and the rich axial ligation chemistry, which affect the above-mentioned luminescence characteristics.

In the case of phosphorous corroles, ${ }^{20}$ an equilibrium between penta-coordinated and hexa-coordinated species has been described, where the latter is prone to undergo axial ligand dissociation forming the penta-coordinated species. The complexes differing in the coordination number can be easily identified by means of UV-vis spectroscopy, where the presence of the sixth ligand induces a redshift and splitting of the Soret band, together with variations in the region of the $Q$ bands in terms of relative absorbance, intensity, and wavelength.

Differently from P-complex, in Si-corrolate, the central atom is normally penta-coordinated. Taking into account the affinity between $\mathrm{Si}$ and F, some of us examined the ability of Si corrole to bind $\mathrm{F}^{-}$to the semimetal center, with the aim to use it as a sensitive material for naked-eye detection of $\mathrm{F}^{-}$, thanks to the large color variation as the result of interaction. ${ }^{18,26}$ Fluoride is an anion with a relevant biological function, with possible detrimental effects if its concentration is either too low or too high. ${ }^{27,28}$ The interaction occurring between halide and silicon ion increases the coordination number of the complex and induces spectroscopic variations similar to those observed in the case of P-corroles.

For the above reasons, in this work, we focus on strongly luminescent (hydroxy)[5,10,15-tritolylcorrolato]silicon(TTC)Si(OH) and (dihydroxy)[5,10,15-tritolylcorrolato]phosphorous-(TTC) $\mathbf{P}(\mathbf{O H})_{2}$ (Scheme 1): we characterize these complexes through magnetic circular dichroism (MCD) spectroscopy and ancillary time-dependent density functional theory (TD-DFT) calculations of the B terms responsible of the recorded spectra.

MCD is a spectroscopic technique, which is quite sensitive to molecular electronic properties and, in particular, to ligand coordination. The basis of MCD theory dates back to the $1960 \mathrm{~s}^{29}$ and nowadays, the possibility of calculating MCD 
A

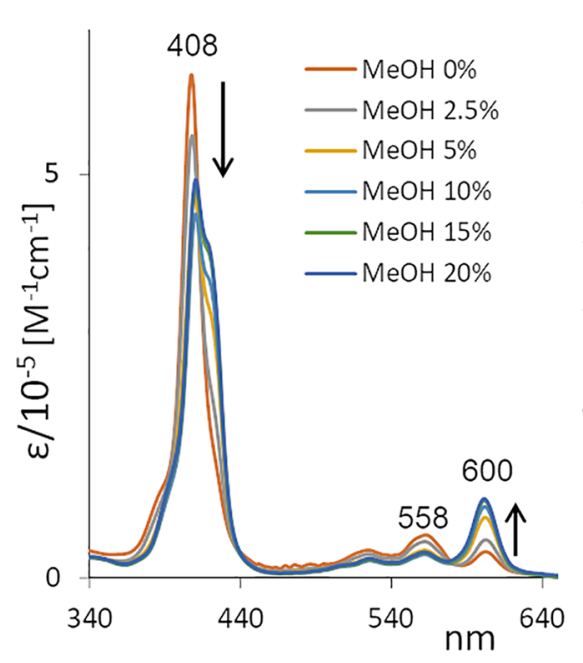

B

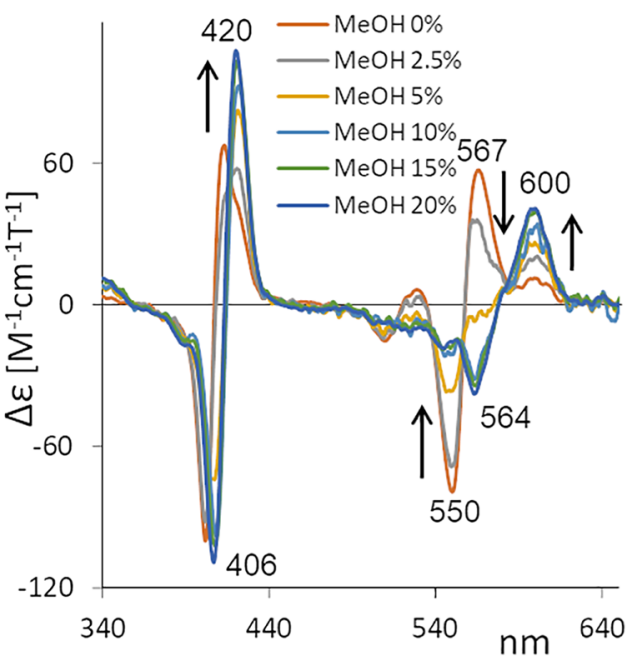

C

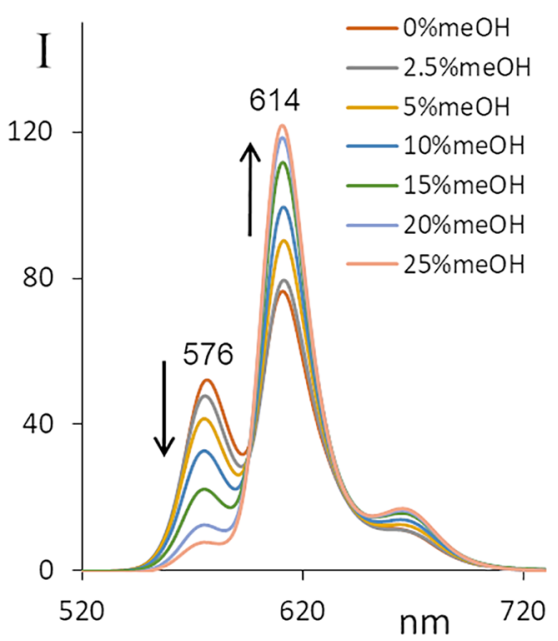

Figure 2. UV-vis (A), MCD (B), and fluorescence (C) spectra of (TTC) $\mathbf{P}(\mathbf{O H})_{2}$ in $\mathrm{CH}_{2} \mathrm{Cl}_{2}$ with subsequent additions of $\mathrm{MeOH}(\% \mathrm{v} / \mathrm{v}$ ). Excitation wavelength: $382 \mathrm{~nm}$.

signals, ${ }^{30-33}$ as implemented in many TD-DFT-based packages, enhances the potentiality of the technique: the agreement between theoretical and experimental results, on the one hand, proves the reliability of the theoretical framework used to represent the molecular system while, on the other hand, allows us to gain more information on the electronic properties of the system under study. ${ }^{34}$ Furthermore, MCD spectroscopy, being particularly sensitive to metal coordination, ${ }^{35,36}$ is found to be the ideal method to follow the axial interaction of metal complexes with various ligands, ${ }^{37}$ thus complementing the information obtained with other optical spectroscopies. Finally, corroles, showing an intense MCD signal in the $\mathrm{Q}$ region and being efficiently excited in correspondence with the Soret band, are good candidates to provide easily detectable magnetic circularly polarized luminescence (MCPL) signals. $^{38-42}$

\section{RESULTS AND DISCUSSION}

UV-Vis and MCD Characterization. Experimental UVvis and MCD spectra for (TTC) $\mathbf{P}(\mathbf{O H})_{2}$ and (TTC) Si(OH) are reported in Figure 1. As commonly observed in corroles, ${ }^{17,21,34,43}$ the doublets recorded in both the Soret and $\mathrm{Q}$ regions show sign-reversal (positive-to-negative intensities while increasing energy) compared to the characteristic MCD spectrum of porphyrin. ${ }^{36,44}$

UV-Vis and MCD Spectra of Phosphorous Corrole: The Role of Solvents. The MCD and UV-vis spectra of (TTC) $\mathbf{P}(\mathrm{OH})_{2}$ are reported for two solvents with relevant differences: $\mathrm{CH}_{2} \mathrm{Cl}_{2}$ (noncoordinating) and methanol (coordinating). Concerning the spectra in $\mathrm{CH}_{2} \mathrm{Cl}_{2}$, the absorption peak at $600 \mathrm{~nm}(2.07 \mathrm{eV})$ corresponds to a weak positive MCD signal, just before a $(+,-)$ doublet with the zero centered at the maximum of the absorption peak at $558 \mathrm{~nm}$ $(2.22 \mathrm{eV})$. In the Soret region, an asymmetric $(+,-)$ doublet is centered at $408 \mathrm{~nm}(3.04 \mathrm{eV})$. The positive component of the doublet displays a broader signal in correspondence of the shoulder in the absorption spectrum at $428 \mathrm{~nm}(2.90 \mathrm{eV})$. Previous work ${ }^{20}$ has shown that in noncoordinating solvents such as $\mathrm{CH}_{2} \mathrm{Cl}_{2}$ or $\mathrm{CDCl}_{3}$ used to record nuclear magnetic resonance (NMR) spectra, the hexa-coordinated complex is prone to undergo ligand loss, thus forming a positively charged penta-coordinated complex. On the other hand, the hexacoordinated geometry is more stable if the solvent has strong coordinating ability; in methanol solution, phosphorous corrole complex with $-\mathrm{OH}$ as axial ligand(s) undergoes ligand exchange, and one or both hydroxyl groups are replaced by the $-\mathrm{OCH}_{3}$ units, ${ }^{20,23}$ as depicted in Scheme 2.

Treatment of a mixture of (TTC) $\mathbf{P}(\mathbf{O H})_{2}$ with coordination numbers 5 and 6 with TFA leads to selectively obtain a pentacoordinated species, characterized by the presence of a $\mathrm{P}=\mathrm{O}$ moiety. $^{45}$

In methanol, the $Q$ region of (TTC) $\mathbf{P}\left(\mathbf{O C H}_{3}\right)_{2}$ displays a broad $(+,-)$ MCD doublet, with the positive component centered at $600 \mathrm{~nm}(2.07 \mathrm{eV})$ (where a weak positive signal is present in $\mathrm{CH}_{2} \mathrm{Cl}_{2}$ ), and an intensity increase is also observed for the corresponding absorption peak. The negative component is observed at $564 \mathrm{~nm}(2.20 \mathrm{eV})$. In the Soret region, the absorption peak clearly arises from two distinct transitions, which correspond to two B terms with opposite sign.

The transition from the penta-coordinated species to the hexa-coordinated dimethoxy derivative can be followed by titrating a $\mathrm{CH}_{2} \mathrm{Cl}_{2}$ solution of (TTC) $\mathbf{P}(\mathrm{OH})_{2}$ with methanol, as reported in Figure $2 \mathrm{~A}-\mathrm{C}$.

By UV-vis spectroscopy, the transition of the complex from penta-coordinated to the hexa-coordinated form is clearly visible by the pattern of $\mathrm{Q}$ bands: while the penta-coordinated form has two main Q bands at 600 and $558 \mathrm{~nm}$, with the latter being the most intense, the presence of two ligands binding the central metal increases the intensity of absorbance of the lower-energy feature and decreases the absorbance of the other Q bands. In the Soret band region, a slight bathochromic shift and the appearance of a shoulder are hallmarks of the hexacoordinate species. The change in coordination pattern of the molecule is more clearly evident on some diagnostic signals of the MCD spectrum: the positive MCD band at $600 \mathrm{~nm}(2.07$ $\mathrm{eV}$ ) is typical of the hexa-coordinated species, as well as the negative band at $564 \mathrm{~nm}(2.20 \mathrm{eV})$. Instead, the negative signal at $550 \mathrm{~nm}(2.25 \mathrm{eV})$, very weak in the presence of methanol, intense and well defined in $\mathrm{CH}_{2} \mathrm{Cl}_{2}$ solution, is a marker of penta-coordinated complex (Figure 2B). Finally, the bisignated 

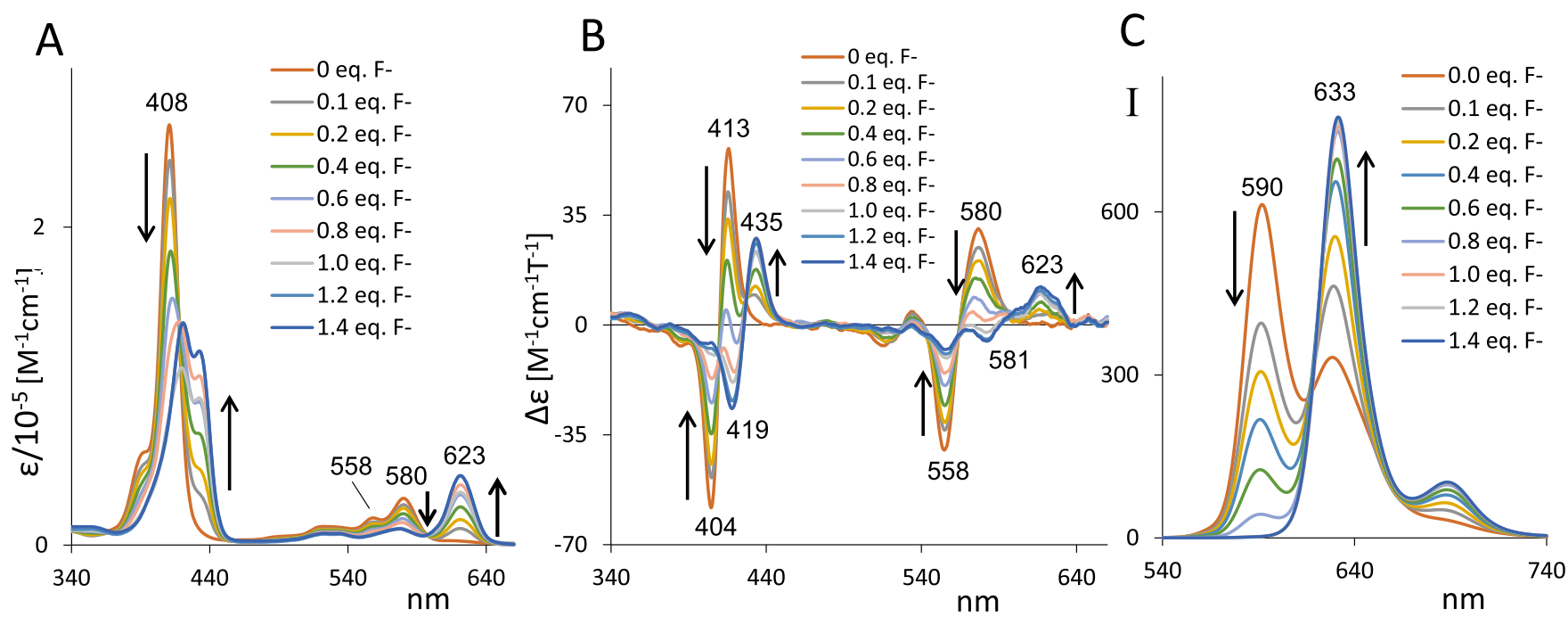

Figure 3. UV-Vis (A), MCD (B), and fluorescence (C) spectra of (TTC)Si(OH) in DMSO with subsequent additions of NaF (number of equivalents reported in the legend). Excitation wavelength: $418 \mathrm{~nm}$.

band in the Soret region is more symmetric after coordination of methanol to yield (TTC) $\mathbf{P}\left(\mathrm{OCH}_{3}\right)_{2}$.

A similar titration has been conducted also by propanol addition (Figure S1), where the complex conversion seems to be a little more difficult (i.e., it requires a larger amount of alcohol to shift the equilibrium) compared to that observed with methanol or by performing TFA-promoted axial ligand exchange. $^{46}$

The same process can be also followed by fluorescence (Figure 2C). In $\mathrm{CH}_{2} \mathrm{Cl}_{2}$ solution, (TTC) $\mathbf{P}(\mathbf{O H})_{2}$ displays a fluorescence spectrum composed of two bands, one at $576 \mathrm{~nm}$ $(2.15 \mathrm{eV})$ and one at $614 \mathrm{~nm}(2.02 \mathrm{eV})$. As we proceed with methanol addition, the band at $576 \mathrm{~nm}$ disappears while the band at $614 \mathrm{~nm}$ increases in intensity. These variations can be addressed to the disappearance of the penta-coordinated complex and the formation of the hexa-coordinated species, respectively ${ }^{20}$ (further details on fluorescence are discussed in the TD-DFT Calculations of Corroles' Electronic Properties section).

UV-Vis and MCD Spectra of Silicon Corrole: Fluoride-Ion Detection by MCD. MCD and UV-vis spectra of (TTC) $\mathrm{Si}(\mathrm{OH})$ in $\mathrm{CH}_{2} \mathrm{Cl}_{2}$ match well with those reported in the literature. ${ }^{17}$ In the $\mathrm{Q}$ region, the MCD spectrum displays a $(+,-)$ doublet, the positive component centered at the absorption peak at $580 \mathrm{~nm}(2.14 \mathrm{eV})$, while the negative component is in correspondence to the second absorption peak at $558 \mathrm{~nm}(2.22 \mathrm{eV})$. The features at about $540-510 \mathrm{~nm}$ have vibronic origin (the energy distance from the $Q$ peak is $\left.1050 \mathrm{~cm}^{-1}\right)$. The Soret region shows the same sign trend as the $Q$ region, i.e., a symmetric $(+,-)$ doublet with the zero at the maximum of the absorption peak at $408 \mathrm{~nm}(3.04 \mathrm{eV})$, a typical shape of two $B$ terms next to each other, with opposite sign (also known as pseudo-A term).

In the case of (TTC) $\mathrm{Si}(\mathrm{OH})$, no solvent-promoted variation of coordination number occurs. However, the strong affinity of Silicon toward $\mathrm{F}^{-}$and the strong luminescence of this tetrapyrrole complex allowed us to use this chromophore for naked-eye detection of fluoride ion in water exploiting the color variation or by measuring the emission variation induced by the binding process. $18,26,47$
Indeed, fluoride was proved to bind to the corrole complex in the axial position; the strong color variation caused by this interaction has been explained in terms of conversion of the pristine penta-coordinated complex into a hexa-coordinated anionic species, as was determined by UV-vis and NMR titration. $^{18}$

MCD and fluorescence sensitivity can be used also to follow titration of the penta-coordinated (TTC) $\mathrm{Si}(\mathrm{OH})$ with fluoride (as $\mathrm{NaF}$ in dimethyl sulfoxide (DMSO) solution) to give a hexa-coordinated anionic species as can be observed through the spectroscopic variations in the UV-vis, MCD, and fluorescence spectra depicted in Figure 3. In a previous work, ${ }^{18}$ we observed that in the DMSO- $\mathrm{H}_{2} \mathrm{O}$ mixture (water content: $10 \% \mathrm{v} / \mathrm{v}$ ), in the absence of $\mathrm{NaF}$, no variation of the $\mathrm{UV}$-vis spectrum occurs, confirming that the inorganic anion induces the coordination number variation.

In particular, in the UV-vis spectrum, the lowest-energy absorption band in the presence of fluoride is observed at 623 $\mathrm{nm}(1.99 \mathrm{eV})$; the intensity of the absorbance increases during the titration process, while the absorption peak at $580 \mathrm{~nm}$ $(2.14 \mathrm{eV})$ decreases. Significant changes are observed in the Soret region, where the band gets split and red-shifted. Such a large variation of the electronic spectrum has been attributed to the large variations induced by fluoride coordination in terms of geometry and charge of the molecule. ${ }^{18}$ Even more evident changes regard the MCD spectra: indeed, one observes the rise of a positive $\mathrm{B}$ term at $623 \mathrm{~nm}(1.99 \mathrm{eV})$, while the initial positive MCD signal at $580 \mathrm{~nm}(2.14 \mathrm{eV})$ inverts sign giving a weak feature at $581 \mathrm{~nm}(2.13 \mathrm{eV})$, similar to that observed during the titration of (TTC) $\mathbf{P}(\mathbf{O H})_{2}$ with methanol. The strong negative $B$ term at $558 \mathrm{~nm}(2.22 \mathrm{eV})$ does not completely disappear during the titration process. In the Soret region, the MCD couplet moves to longer wavelength, and the splitting between the positive and negative components becomes slightly larger, increasing from 12 to 14 nm. In Figure S2, we compare the MCD and UV-vis spectra of (TTC) $\mathrm{Si}(\mathrm{OH})$ in $\mathrm{CH}_{2} \mathrm{Cl}_{2}$ and DMSO: no significant solvent effect was observed, corroborating the hypothesis that the variation is induced only by the interaction with the inorganic ligand. 

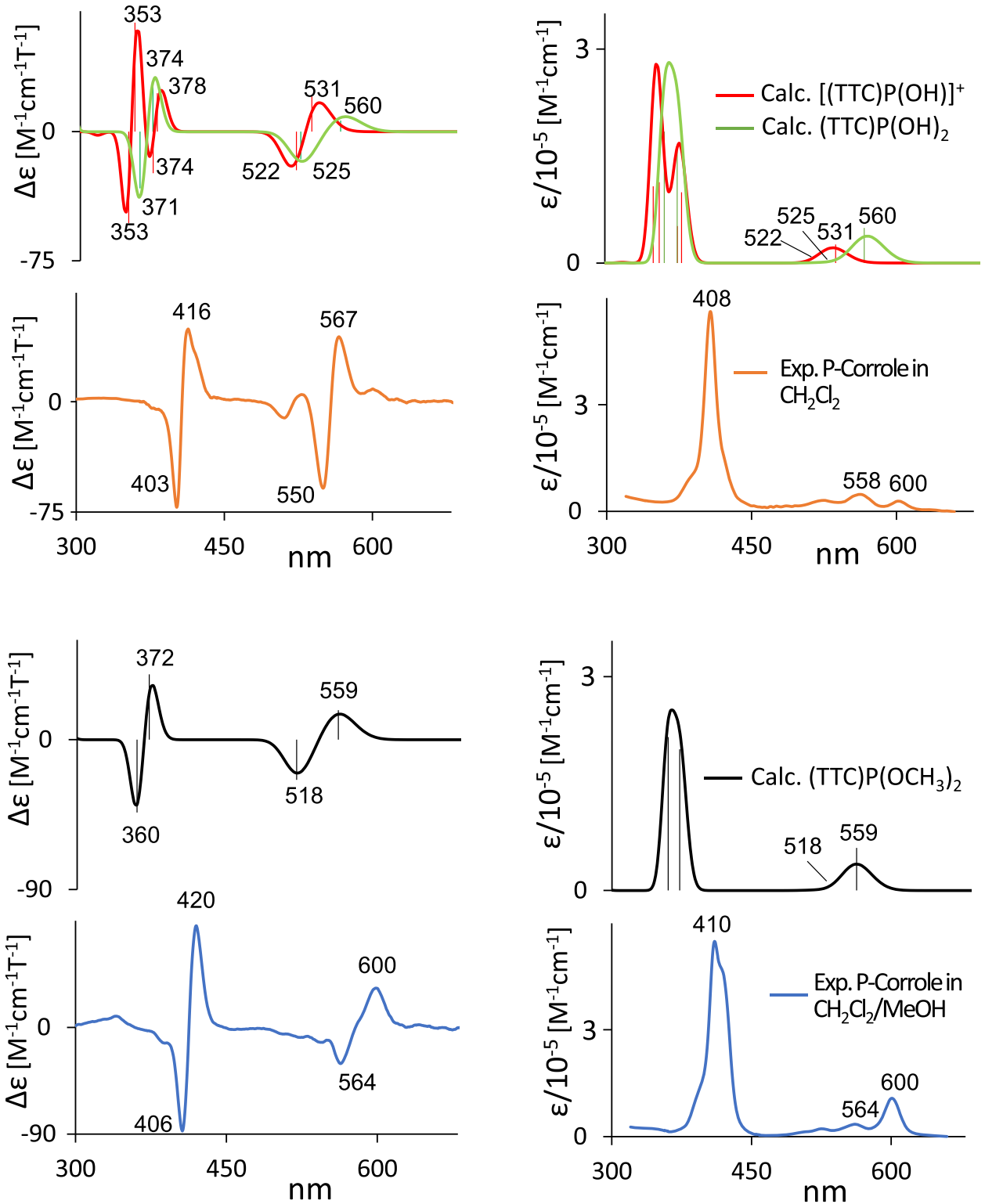

Figure 4. Comparison of experimental $\mathrm{MCD}$ and $\mathrm{UV}$-vis spectra of phosphorous corrole in $\mathrm{CH}_{2} \mathrm{Cl}_{2}$ (top) and $\mathrm{MeOH}$ (bottom) solutions with the corresponding calculated one (see text).

Considering fluorescence spectra, the band at $590 \mathrm{~nm}(2.10$ $\mathrm{eV})$ disappears while the band at $633 \mathrm{~nm}(1.96 \mathrm{eV})$ together with the shoulder at $690 \mathrm{~nm}(1.80 \mathrm{eV})$ increases in intensity during the titration process, as already observed. In all three instances (UV-vis, MCD, and fluorescence spectra), isosbestic points are observed, proving the coexistence of two independent species. Due to the differences observed in the absorption region of the Soret band (Figure 3A), to obtain fluorescence spectra, we used the excitation wavelength corresponding to the isosbestic point in absorption, namely, $\lambda=418 \mathrm{~nm}$.

The absorption and fluorescence spectra compare well with previously reported data, ${ }^{18}$ confirming a linear change of the absorbance and fluorescence intensities with addition of fluoride, showing an end point slightly over 1 equiv of the guest molecule (see also Figure S4).

TD-DFT Calculations of Corroles' Electronic Properties. After optimization of the ground-state geometry of corroles, experimental MCD and UV-vis spectra have been interpreted by TD-DFT calculations. Calculated spectra presented in Figures 4-6 contain only pure electronic transitions, with no account of any vibronic contributions. This means that we cannot reproduce all of the details of the $Q$ band features.

Phosphorous Corrole Ground-State Properties. The interpretation of phosphorous corrole spectra is challenging. In Figure 4, we compare the experimental spectra of phosphorous corrole in $\mathrm{CH}_{2} \mathrm{Cl}_{2}$ (Figure 4, top) and methanol solutions (Figure 4, bottom) with the corresponding calculated ones. In $\mathrm{CH}_{2} \mathrm{Cl}_{2}$, both the penta-coordinated (TTC) $\mathbf{P}(\mathbf{O H})^{+}$and hexacoordinated (TTC) $\mathbf{P}(\mathbf{O H})_{2}$ complexes have been considered. The calculated electronic transitions reported in Table 1 reproduce the main features of the experimental spectra. The electronic transitions are calculated to have higher energy compared to the experimental data, as expected with longrange corrected functionals like CAM-B3LYP. ${ }^{48}$ We recall that other functional choices are present in the literature for other corroles $^{21,43,49}$ or in TD-DFT benchmark studies ${ }^{50,51}$ on other 
Table 1. Calculated Properties for Transitions Corresponding to the Observed Bands: Excitation Energy $\omega$ (eV), Corresponding Wavelength $\lambda(\mathrm{nm})$, Oscillator Strength $(f)$, Faraday B Term ${ }^{b}($ au $)$, Wavefunctions

\begin{tabular}{|c|c|c|c|c|}
\hline$\omega(\mathrm{eV})$ & $\lambda(\mathrm{nm})$ & $f$ & $\mathrm{~B}$ term $(\mathrm{au})$ & transition descriptions in terms of wavefunctions ${ }^{a}$ \\
\hline \multicolumn{5}{|c|}{$[(\mathbf{T T C}) \mathbf{P}(\mathbf{O H})]^{+}$} \\
\hline 2.33 & 531 & 0.11 & 409.2 & $\mathrm{H}\left(\mathrm{a}^{\prime}\right) \rightarrow \mathrm{L}\left(\mathrm{a}^{\prime \prime}\right) 64 \%, \mathrm{H}-1\left(\mathrm{a}^{\prime \prime}\right) \rightarrow \mathrm{L}+1\left(\mathrm{a}^{\prime}\right) 33 \%$ \\
\hline 2.37 & 522 & 0.001 & -446.6 & $\mathrm{H}-1\left(\mathrm{a}^{\prime \prime}\right) \rightarrow \mathrm{L}\left(\mathrm{a}^{\prime \prime}\right) 54 \%, \mathrm{H}\left(\mathrm{a}^{\prime}\right) \rightarrow \mathrm{L}+1\left(\mathrm{a}^{\prime}\right) 43 \%$ \\
\hline 3.28 & 378 & 0.61 & 848.3 & $\mathrm{H}-1\left(\mathrm{a}^{\prime \prime}\right) \rightarrow \mathrm{L}+2\left(\mathrm{a}^{\prime}\right) 37 \%, \mathrm{H}-1\left(\mathrm{a}^{\prime \prime}\right) \rightarrow \mathrm{L}+1\left(\mathrm{a}^{\prime}\right) 41 \%$ \\
\hline 3.32 & 374 & 0.32 & -915.1 & $\mathrm{H}\left(\mathrm{a}^{\prime}\right) \rightarrow \mathrm{L}+2\left(\mathrm{a}^{\prime}\right) 55 \%, \mathrm{H}\left(\mathrm{a}^{\prime}\right) \rightarrow \mathrm{L}+1\left(\mathrm{a}^{\prime}\right) 22 \%, \mathrm{H}-1\left(\mathrm{a}^{\prime \prime}\right) \rightarrow \mathrm{L}\left(\mathrm{a}^{\prime \prime}\right) 20 \%$ \\
\hline 3.51 & 353 & 0.75 & 2216.1 & $\mathrm{H}\left(\mathrm{a}^{\prime}\right) \rightarrow \mathrm{L}+2\left(\mathrm{a}^{\prime}\right) 37 \%, \mathrm{H}\left(\mathrm{a}^{\prime}\right) \rightarrow \mathrm{L}+1\left(\mathrm{a}^{\prime}\right) 28 \%, \mathrm{H}-1\left(\mathrm{a}^{\prime \prime}\right) \rightarrow \mathrm{L}\left(\mathrm{a}^{\prime \prime}\right) 20 \%$ \\
\hline 3.53 & 351 & 0.72 & -2015.9 & $\mathrm{H}-1\left(\mathrm{a}^{\prime \prime}\right) \rightarrow \mathrm{L}+2\left(\mathrm{a}^{\prime}\right) 51 \%, \mathrm{H}-1\left(\mathrm{a}^{\prime \prime}\right) \rightarrow \mathrm{L}+1\left(\mathrm{a}^{\prime}\right) 38 \%$ \\
\hline \multicolumn{5}{|c|}{$(\mathrm{TTC}) \mathbf{P}(\mathrm{OH})_{2}$} \\
\hline 2.21 & 560 & 0.20 & 97.3 & $\mathrm{H}\left(\mathrm{b}_{1}\right) \rightarrow \mathrm{L}\left(\mathrm{a}_{2}\right) 78 \%, \mathrm{H}-1\left(\mathrm{a}_{2}\right) \rightarrow \mathrm{L}+1\left(\mathrm{~b}_{1}\right) 21 \%$ \\
\hline 2.39 & 525 & 0.004 & -191.9 & $\mathrm{H}-1\left(\mathrm{a}_{2}\right) \rightarrow \mathrm{L}\left(\mathrm{a}_{2}\right) 55 \%, \mathrm{H}\left(\mathrm{b}_{1}\right) \rightarrow \mathrm{L}+1\left(\mathrm{~b}_{1}\right) 53 \%$ \\
\hline 3.33 & 374 & 1.04 & 292.6 & $\mathrm{H}\left(\mathrm{b}_{1}\right) \rightarrow \mathrm{L}+1\left(\mathrm{~b}_{1}\right) 57 \%, \mathrm{H}-1\left(\mathrm{a}_{2}\right) \rightarrow \mathrm{L}\left(\mathrm{a}_{2}\right) 43 \%$ \\
\hline 3.45 & 361 & 1.20 & -329.7 & $\mathrm{H}-1\left(\mathrm{a}_{2}\right) \rightarrow \mathrm{L}+1\left(\mathrm{~b}_{1}\right) 77 \%, \mathrm{H}\left(\mathrm{b}_{1}\right) \rightarrow \mathrm{L}\left(\mathrm{a}_{2}\right) 21 \%$ \\
\hline \multicolumn{5}{|c|}{$(\mathrm{TTC}) \mathrm{P}\left(\mathrm{OCH}_{3}\right)_{2}$} \\
\hline 2.22 & 559 & 0.20 & 175.4 & $\mathrm{H}\left(\mathrm{b}_{1}\right) \rightarrow \mathrm{L}\left(\mathrm{a}_{2}\right) 79 \%, \mathrm{H}-1\left(\mathrm{a}_{2}\right) \rightarrow \mathrm{L}+1\left(\mathrm{~b}_{1}\right) 20 \%$ \\
\hline 2.39 & 518 & 0.004 & -221.5 & $\mathrm{H}-1\left(\mathrm{a}_{2}\right) \rightarrow \mathrm{L}\left(\mathrm{a}_{2}\right) 56 \%, \mathrm{H}\left(\mathrm{b}_{1}\right) \rightarrow \mathrm{L}+1\left(\mathrm{~b}_{1}\right) 42 \%$ \\
\hline 3.34 & 372 & 1.00 & 393.9 & $\mathrm{H}\left(\mathrm{b}_{1}\right) \rightarrow \mathrm{L}+1\left(\mathrm{~b}_{1}\right) 57 \%, \mathrm{H}-1\left(\mathrm{a}_{2}\right) \rightarrow \mathrm{L}\left(\mathrm{a}_{2}\right) 42 \%$ \\
\hline 3.44 & 360 & 1.13 & -330.1 & $\mathrm{H}-1\left(\mathrm{a}_{2}\right) \rightarrow \mathrm{L}+1\left(\mathrm{~b}_{1}\right) 77 \%, \mathrm{H}\left(\mathrm{b}_{1}\right) \rightarrow \mathrm{L}\left(\mathrm{a}_{2}\right) 10 \%$ \\
\hline \multicolumn{5}{|c|}{$(\mathrm{TTC}) \mathrm{Si}(\mathrm{OH})$} \\
\hline 2.28 & 544 & 0.15 & 514.3 & $\mathrm{H}\left(\mathrm{a}^{\prime}\right) \rightarrow \mathrm{L}\left(\mathrm{a}^{\prime \prime}\right) 81 \%, \mathrm{H}-1\left(\mathrm{a}^{\prime \prime}\right) \rightarrow \mathrm{L}+1\left(\mathrm{a}^{\prime}\right) 16 \%$ \\
\hline 2.38 & 521 & 0.01 & -529.6 & $\mathrm{H}-1\left(\mathrm{a}^{\prime \prime}\right) \rightarrow \mathrm{L}\left(\mathrm{a}^{\prime \prime}\right) 55 \%, \mathrm{H}\left(\mathrm{a}^{\prime}\right) \rightarrow \mathrm{L}+1\left(\mathrm{a}^{\prime}\right) 42 \%$ \\
\hline 3.43 & 363 & 1.15 & 1084.2 & $\mathrm{H}\left(\mathrm{a}^{\prime}\right) \rightarrow \mathrm{L}+1\left(\mathrm{a}^{\prime}\right) 56 \%, \mathrm{H}-1\left(\mathrm{a}^{\prime \prime}\right) \rightarrow \mathrm{L}\left(\mathrm{a}^{\prime \prime}\right) 43 \%$ \\
\hline 3.44 & 360 & 1.38 & -1117.9 & $\mathrm{H}-1\left(\mathrm{a}^{\prime \prime}\right) \rightarrow \mathrm{L}+1\left(\mathrm{a}^{\prime}\right) 78 \%, \mathrm{H}\left(\mathrm{a}^{\prime}\right) \rightarrow \mathrm{L}\left(\mathrm{a}^{\prime \prime}\right) 18 \%$ \\
\hline \multicolumn{5}{|c|}{$[(\mathrm{TTC}) \mathrm{Si}(\mathrm{OH})(\mathrm{F})]^{-}$} \\
\hline 2.09 & 593 & 0.24 & 157.2 & $\mathrm{H}\left(\mathrm{a}^{\prime}\right) \rightarrow \mathrm{L}\left(\mathrm{a}^{\prime \prime}\right) 81 \%, \mathrm{H}-1\left(\mathrm{a}^{\prime \prime}\right) \rightarrow \mathrm{L}+1\left(\mathrm{a}^{\prime}\right) 16 \%$ \\
\hline 2.29 & 542 & 0.003 & -187.2 & $\mathrm{H}-1\left(\mathrm{a}^{\prime \prime}\right) \rightarrow \mathrm{L}\left(\mathrm{a}^{\prime \prime}\right) 55 \%, \mathrm{H}\left(\mathrm{a}^{\prime}\right) \rightarrow \mathrm{L}+1\left(\mathrm{a}^{\prime}\right) 42 \%$ \\
\hline 3.13 & 396 & 1.03 & 227.3 & $\mathrm{H}\left(\mathrm{a}^{\prime}\right) \rightarrow \mathrm{L}+1\left(\mathrm{a}^{\prime}\right) 56 \%, \mathrm{H}-1\left(\mathrm{a}^{\prime \prime}\right) \rightarrow \mathrm{L}\left(\mathrm{a}^{\prime \prime}\right) 43 \%$ \\
\hline 3.29 & 377 & 1.09 & -167.9 & $\mathrm{H}-1\left(\mathrm{a}^{\prime \prime}\right) \rightarrow \mathrm{L}+1\left(\mathrm{a}^{\prime}\right) 78 \%, \mathrm{H}\left(\mathrm{a}^{\prime}\right) \rightarrow \mathrm{L}\left(\mathrm{a}^{\prime \prime}\right) 18 \%$ \\
\hline
\end{tabular}

${ }^{a} \mathrm{H}=\mathrm{HOMO} ; \mathrm{L}=$ LUMO. Symmetry group and species established disregarding tolyl group orientation. ${ }^{b} \mathrm{~B}$ terms are reported using the sign convention of Piepho and Schatz, ${ }^{56}$ that is, the sign of B term corresponds to the one given by the spectrometer with the magnetic field parallel to the direction of the light beam.

macrocycles: calculated transition energies are either red- or blue-shifted, with respect to experimental ones, and depending on the chosen functional, the calculated energy levels result in a too high HOMO-LUMO difference in the case of longrange corrected functional like the one adopted here. ${ }^{51}$ This notwithstanding, we chose CAM-B3LYP since it shows acceptable excitation energy values and relative absorption intensities; furthermore, a test of MCD spectrum calculation showed a better shape considering CAM-B3LYP in comparison to B3LYP.

The molecular orbitals involved in the transitions agree with the Gouterman model, ${ }^{25}$ which is based on the configuration interactions between the four frontier orbitals. The assignment of the electronic transitions is reported in Table 1, while the representation of the involved molecular orbitals is reported in Figure S5. Considering the energy levels in the same figure, we notice that the energy difference between the occupied frontier orbitals $\left(\Delta_{\mathrm{HOMO}}\right)$ is smaller than for the unoccupied frontier orbitals $\left(\Delta_{\text {LUMO }}\right)$; therefore, a $(+,-)$ couplet is observed, as expected according to the Michl model ${ }^{52-54}$ and as obtained in many other corrole systems. ${ }^{21,43,49}$ We recall here that in corroles, the trend $(+,-)$ is reversed with respect to the usually observed $(-,+)$ behavior in porphyrins. ${ }^{35,36}$

In all cases, two transitions are calculated for the $Q$ band $\left(Q_{x}\right.$ and $Q_{y}$, respectively), having opposite $B$ terms. The second electronic transition possesses a very low oscillator strength being forbidden for symmetry reasons but has a B term comparable (and opposite) to the one of the lowest-energy transition.

In the case of the penta-coordinated phosphorous corrole, the two transitions are nearly degenerate, resulting in a doublet that has the appearance of a pseudo-A term. ${ }^{55}$ Four electronic transitions are calculated in the Soret region, two of which (centered at $378 \mathrm{~nm}(3.28 \mathrm{eV})$ and $374 \mathrm{~nm}(3.32 \mathrm{eV})$ ) are responsible for the lower-energy shoulder of the Soret absorption band and for the positive MCD component, while the next two transitions (centered at $353 \mathrm{~nm}(3.51 \mathrm{eV}$ ) and at $351 \mathrm{~nm}(3.53 \mathrm{eV}))$ contribute to the most intense absorption signal and to the MCD couplet.

Considering next the hexa-coordinated complex, we notice that the first transition calculated at $560 \mathrm{~nm}(2.21 \mathrm{eV})$ is at lower energy than the corresponding one of the pentacoordinated complex and is also more intense. This transition is responsible for the observed absorption signal and for the positive MCD signal at $600 \mathrm{~nm}(2.07 \mathrm{eV})$. Moreover, the transition computed at $374 \mathrm{~nm}(3.33 \mathrm{eV})$ can contribute to the shoulder in absorption and to the positive MCD signal in the Soret region.

In Figure S6, we report the comparison of experimental and calculated spectra referred to energy $(\mathrm{eV}) x$-axis.

The hexa-coordinated complex (TTC) $\mathbf{P}\left(\mathbf{O C H}_{3}\right)_{2}$ was calculated to simulate the situation in methanol. The computed results show four transitions, which determine the features experimentally observed (see Table 1). The first transition is calculated at $559 \mathrm{~nm}(2.22 \mathrm{eV})$, almost in the 

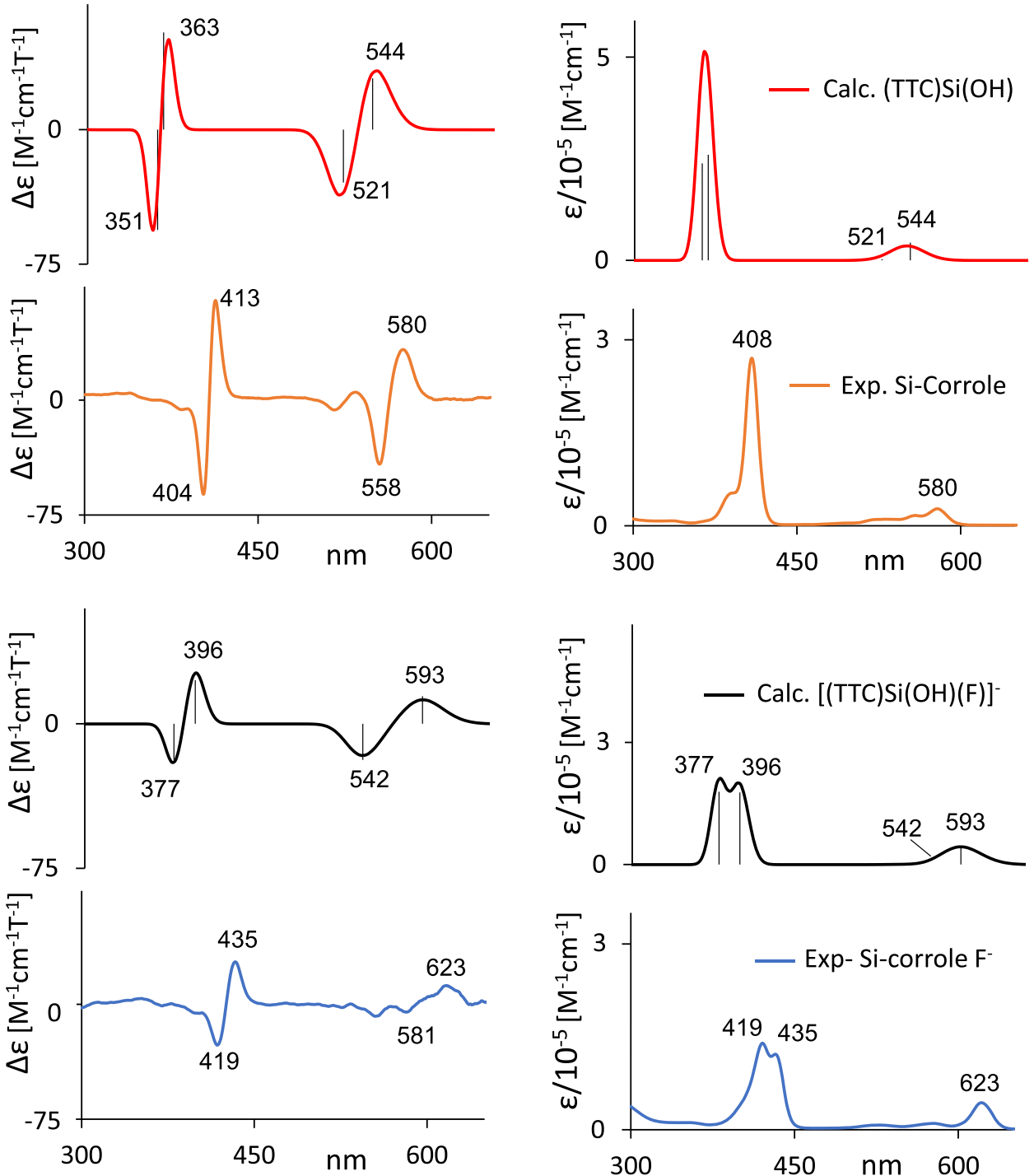

Figure 5. Comparison of experimental UV-vis and MCD spectra of penta-coordinated (orange line) and hexa-coordinated (blue line) silicon corrole with the corresponding calculated spectra for penta-coordinated (red line) and hexa-coordinated (black line) species.

same position of the corresponding transition of hexacoordinated (TTC) $\mathbf{P}(\mathbf{O H})_{2}$, as observed from experimental data (see Figure 2A).

In conclusion, the calculated electronic transitions reported in Table 1 reproduce the main features of the experimental spectra; in particular, they allow one to explain the differences of observed wavelengths for the MCD and absorption features, when comparing $\mathrm{CH}_{2} \mathrm{Cl}_{2}$ to $\mathrm{CH}_{3} \mathrm{OH}$ solutions.

(TTC)Si(OH) Ground-State Properties. The optimized structure of hydroxy $\mathrm{Si}$ corrole is in accordance with the one obtained by X-ray analysis ${ }^{18}$ (see geometric parameters in Table S1): spectra have been computed for both the pentacoordinated hydroxy silicon corrole and the hexa-coordinated anionic fluoride complex.

Four electronic transitions are responsible for the four MCD $\mathrm{B}$ terms of the two experimentally observed doublets, as reported in Figure 5 and Table 1.

TD-DFT calculations not only predict the main characteristics of MCD and UV-vis spectra with the usual frame of involved orbitals but also correctly reproduce the experimental trend of the MCD bands in going from the (TTC) $\mathrm{Si}(\mathrm{OH})$ to the $[(\mathrm{TTC}) \mathrm{Si}(\mathrm{OH})(\mathrm{F})]^{-}$form of complex (Figure 5). The calculated UV-vis spectrum for $[(\mathrm{TTC}) \mathrm{Si}(\mathrm{OH})(\mathrm{F})]^{-}$reproduces the splitting of the Soret band and the redshift experimentally observed, as well as the change in intensity of the signals, both in absorption and MCD, are well accounted for. In Figure S7, we report the comparison of experimental and calculated spectra referred to energy $(\mathrm{eV}) x$-axis.

The $[(\mathbf{T T C}) \mathrm{Si}(\mathbf{O H})(\mathbf{F})]^{-}$geometry shows a larger deviation from planarity $\left(\chi_{1}=19.7^{\circ}, \chi_{2}=-9.6^{\circ}, \chi_{3}=6.5^{\circ}\right.$, $\psi_{1}=5.9^{\circ}$ ) with respect to the penta-coordinated (TTC)Si$(\mathbf{O H})$, as can be appreciated from Table S1: the structural change originates the splitting of the Soret band.

Excited-State Properties. For the calculations of fluorescence and MCPL response, corroles geometries were optimized in the first excited state $\left(S_{1}\right)$. The geometrical parameters for Si corrole, reported in Table S2, change slightly from the ground state to the excited state. Both $\mathrm{N}-\mathrm{Si}$ and $\mathrm{C}-$ $\mathrm{C}$ bonds are stretched in the excited-state geometry with respect to the ground-state geometry (GS); instead, $\mathrm{N}-\mathrm{N}$ distances slightly decrease with respect to the GS geometry. Moreover, the so-called ruffling $(\psi)$ and saddle $(\chi)$ dihedrals $^{57,58}$ slightly increase their value in the excited-state structure. 

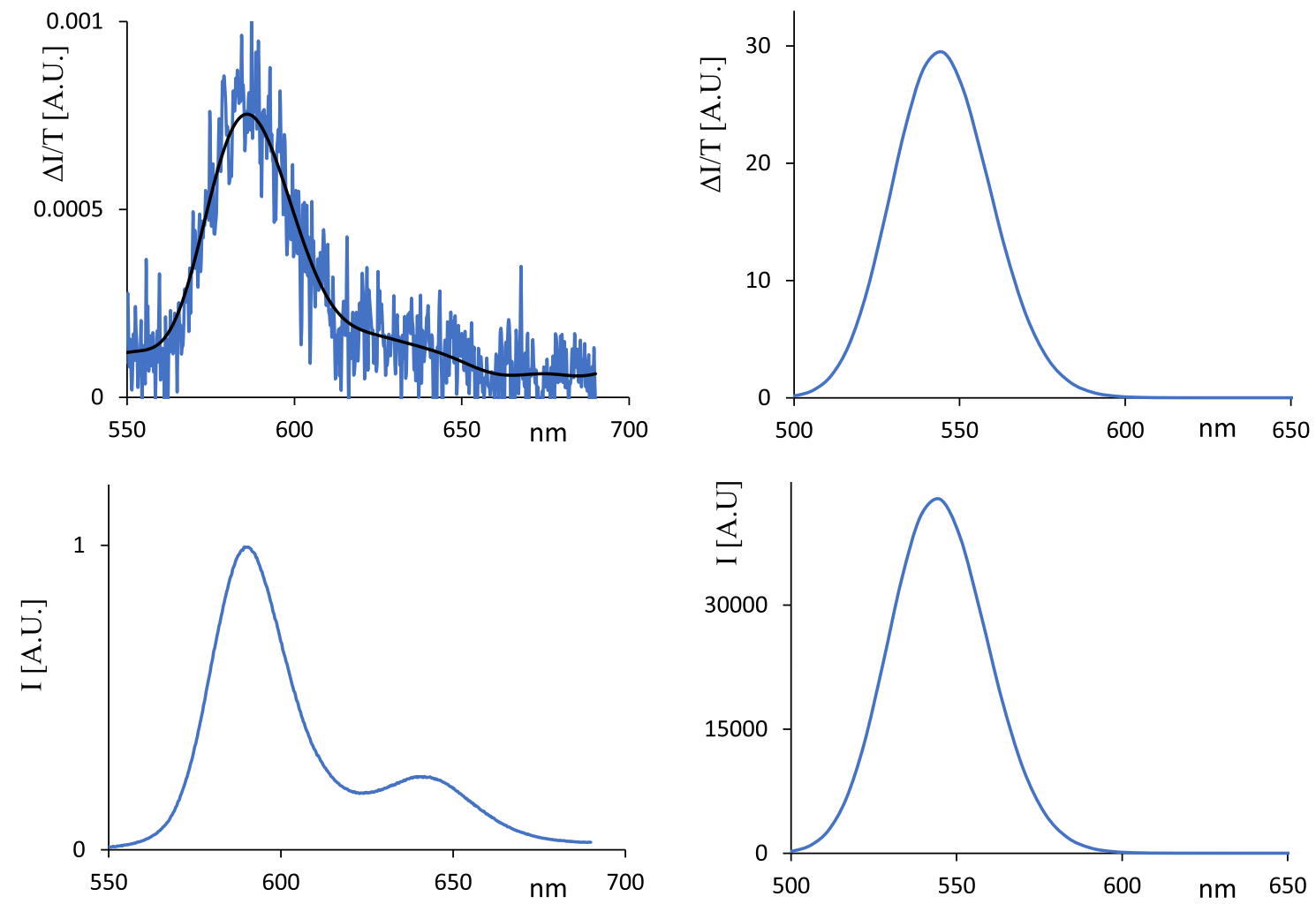

Figure 6. Comparison of experimental (left) and calculated (right) MCPL (top) and fluorescence (bottom) spectra of (TTC)Si(OH).

Magnetic optical activity can be observed also in emission. ${ }^{56,59}$ Such a phenomenon is called magnetic circularly polarized luminescence (MCPL) and measures the difference between right and left circularly polarized emission due to the external magnetic field. Even if the number of recorded MCPL spectra is still limited, data produced by this technique have been spreading lately. ${ }^{38-42}$

We measured MCPL spectra of (TTC) $\mathrm{Si}(\mathbf{O H})$ (Figure 6), and, to the best of our knowledge, our data are the first ever reported for corrole systems. The excitation wavelength was at the center of the Soret band at $408 \mathrm{~nm}$.

As already observed for other tetrapyrrole macrocycles such as porphyrin and porphyrazine, the sign of MCPL band coincides with the one of the lower-energy bands of MCD (holding the same magnetic field orientation with respect to the light beam). This characteristic behavior is also typical of CPL with respect to $C D$ in most cases, when there is no major geometry change in the excited state with respect to the ground state. ${ }^{60-62}$

Even though the spectrum has poor resolution, it is possible to still recognize the presence of a second component at about $640 \mathrm{~nm}(1.94 \mathrm{eV})$, as observed in the fluorescence spectrum.

Since MCPL is the emission analogue of MCD, MCPL is proportional to the Faraday term calculated for the excitedstate geometry, in a similar way to that done for the CPL calculations. Thus, for the transition $S_{1} \rightarrow S_{0}$, we calculated a positive $\mathrm{B}$ term centered at $541 \mathrm{~nm}(2.29 \mathrm{eV})$.

We consider also TD-DFT calculations for the interpretation of the (TTC) $\mathbf{P}(\mathbf{O H})_{2}$ fluorescence data shown in Figure 2C. Calculations support the argument regarding the presence of two phosphorous corrole species in $\mathrm{CH}_{2} \mathrm{Cl}_{2}$ solution. Indeed, the fluorescence of the penta-coordinated species is calculated at $533 \mathrm{~nm}(2.33 \mathrm{eV})$, while the fluorescence for the hexa-coordinated species is calculated at $566 \mathrm{~nm}(2.19 \mathrm{eV})$.
The separation of these two bands $(0.14 \mathrm{eV})$ is similar to that experimentally observed $(0.12 \mathrm{eV})$ in $\mathrm{CH}_{2} \mathrm{Cl}_{2}$. The fluorescence of the (TTC) $\mathbf{P}\left(\mathbf{O C H}_{3}\right)_{2}$ species is calculated at 569 $\mathrm{nm}(2.18 \mathrm{eV})$, matching in energy with the fluorescence of (TTC) $\mathbf{P}(\mathbf{O H})_{2}$ as observed in the titration fluorescence experiments (see Figure S8 for a comparison of calculated and experimental fluorescence spectra).

\section{CONCLUSIONS}

Two corrole systems have been examined principally with the aid of MCD spectroscopy and TD-DFT calculations thereof. The use of the MCD technique is not new in the characterization of corroles: in particular, it is well known how these compounds present a typical sign-reversal of the Soret and $\mathrm{Q}$ features with respect to the porphyrin case. The intriguing behavior of corroles derivatives is explained in the framework of the Michl scheme or by the Gouterman model: that is to say, $\Delta_{\text {HOMO }}$ is lower than $\Delta_{\text {LUMO }}$. In this work, we have shown the high sensitivity of this technique in evidencing changes of corrole in sensing different environments in both cases of the $\mathrm{Si}(\mathrm{IV})$ and $\mathrm{P}(\mathrm{V})$ complexes. In the case of $\mathrm{P}$ corrole, the outcome of $\mathrm{MCD}$ analysis is sensitive to the transformation occurring by replacing $\mathrm{CH}_{2} \mathrm{Cl}_{2}$ with $\mathrm{CH}_{3} \mathrm{OH}$ as the solvent, where the cationic penta-coordinated $\mathrm{P}(\mathrm{V})$ complex with one hydroxyl group as axial ligand is converted into the neutral hexa-coordinated with two alkoxy units axially bound.

MCD spectroscopy underlines a similar change of coordination also in the case of (TTC)Si(OH): for the complex, the variation is induced by interaction with fluoride, allowing the exploitation of this tetrapyrrole as sensitive material for optical sensing. In general, MCD spectroscopy shows a better resolution of the electronic transitions with respect to absorption spectroscopy due to the presence of 
bands of opposite sign, besides that the intensity rules are different, as an example, we evidenced that in the $Q$ region, a transition can be electric dipole-forbidden and small in absorption intensity, while it exhibits significant MCD response. Calculations not only of the electronic levels and their associated orbitals but also of the B terms accounting for the observed spectra offer cogent evidence of the appropriateness of the model provided by the TD-DFT approach. Apart from vibronic effects, herein not considered, the most evident changes observed in the two titration experiments are well accounted for by calculations.

Last but not least, having corrole good fluorescence response upon excitation at the Soret band, these complexes are good candidates as MCPL responsive systems: we could indeed prove that fact through the investigation of the brilliant $\mathrm{Si}$ corrole coupled with TD-DFT calculation of the response.

\section{EXPERIMENTAL AND COMPUTATIONAL METHODS}

Experimental Methods. (TTC) $\mathrm{Si}(\mathrm{OH})$ and (TTC)P$(\mathrm{OH})_{2}$ have been prepared as reported in the literature. ${ }^{18,20,63}$

UV-vis absorption and magnetic circular dichroism (MCD) spectra were recorded in the UV-vis range using a J-815SE spectrometer, equipped with a home-built cell holder hosting neodymium-based magnets producing $1 \mathrm{~T}$ magnetic field in a $0.5 \mathrm{~cm}$ pathlength quartz cell. The measurements were performed on ca. $10^{-5}-10^{-6} \mathrm{M}$ solutions at room temperature. Ten scans were taken for each orientation of the magnetic field (either parallel or antiparallel to the light beam). Good mirror image for parallel and antiparallel orientation was checked. In the figures, we plotted the MCD spectra corresponding to the parallel orientation of the magnetic field.

Fluorescence spectra were recorded with a Jasco FP8600 spectrofluorometer; $10^{-6} \mathrm{M}$ solutions were measured with 1 $\mathrm{cm}$ pathlength quartz cells and $2 \mathrm{~nm}$ excitation bandwidth. MCPL spectra and their relative fluorescence were measured using a home-built apparatus designed for $\mathrm{CPL}^{64,65}$ for $10^{-6} \mathrm{M}$ solutions using $1 \mathrm{~cm}$ pathlength quartz cuvette, $20 \mathrm{~nm} / \mathrm{min}$ scanning speed, $20 \mathrm{~nm}$ excitation bandwidth, 10 scans per measurement for either parallel or antiparallel orientation, $90^{\circ}$ geometry, with $0.4 \mathrm{~T}$ magnetic field parallel to the collected radiation beam, as done previously. ${ }^{38}$

Titration of (TTC)Si( $\mathrm{OH})$ with fluoride ion was carried out in DMSO, adding small volumes of $\mathrm{NaF}$, previously dissolved in a $\mathrm{DMSO} /$ water solution.

Computational Methods. Optimization of molecular structures was performed using Gaussian 16 package ${ }^{66}$ at the BP86/6-311+G* level of theory combined with Grimme's D3 correction. ${ }^{67}$

Excitation energies, oscillator strengths, and MCD B terms ${ }^{68}$ were calculated using Dalton2016 code ${ }^{69,70}$ within the linear response formulation of TD-DFT at the CAM-B3LYP/6$311+\mathrm{G}^{*}$ level of theory. A Gaussian shape function was used for presenting computed spectra from calculated transitions (bandwidth $=500 \mathrm{~cm}^{-1}$ ).

Fluorescence and MCPL responses were obtained by first optimizing the structure of the first excited electronic state and then by computing the electronic properties (excitation energy, oscillator strength, and B term) by TD-DFT CAM-B3LYP/6$311+\mathrm{G}^{*}$.

Molecular orbitals were represented using Molden software. $^{71}$

\section{ASSOCIATED CONTENT}

\section{Supporting Information}

The Supporting Information is available free of charge at https://pubs.acs.org/doi/10.1021/acsomega.1c04028.

MCD and UV-vis spectra of (TTC) $\mathbf{P}(\mathrm{OH})_{2}$ in $\mathrm{CH}_{2} \mathrm{Cl}_{2}$ titrated with propanol (Figure $\mathrm{S} 1$ ); experimental $\mathrm{MCD}$ and UV-vis spectra of (TTC) $\mathrm{Si}(\mathrm{OH})$ in $\mathrm{CH}_{2} \mathrm{Cl}_{2}$ and DMSO (Figure S2); conversion of (TTC)Si $(\mathbf{O H})$ into $[(\mathrm{TTC}) \mathrm{Si}(\mathbf{O H})(\mathbf{F})]^{-}$(Figure S3); titration plot of (TTC)Si(OH) with NaF (Figure S4); frontier molecular orbitals for silicon and phosphorous corroles (Figure S5); comparison of experimental UV-vis and MCD spectra of phosphorous corrole with the corresponding calculated spectra ( $\mathrm{eV}$ on $x$-axes) (Figure S6); comparison of experimental UV-vis and MCD spectra of silicon corrole with the corresponding calculated spectra (eV on $x$-axes) (Figure S7); calculated values of ruffling $(\psi)$ and saddle $(\chi)$ dihedrals angles of silicon and phosphorous corroles (Table S1); calculated values of bond lengths and dihedral angles of silicon corrole in the ground state (GS) and in the first excited state $\left(S_{1}\right)$ (Table S2); and calculated and experimental phosphorous corrole fluorescence (Figure S8) (PDF)

\section{AUTHOR INFORMATION}

\section{Corresponding Authors}

Giuseppe Pomarico - Department of Molecular and Translational Medicine, University of Brescia, 25123 Brescia, Italy; CSGI, Research Center for Colloids and Nanoscience, 50019 Firenze, Italy; ๑ orcid.org/0000-0003-3029-7063; Email: giuseppe.pomarico@unibs.it

Giovanna Longhi - Department of Molecular and Translational Medicine, University of Brescia, 25123 Brescia, Italy; National Institute of Optics (INO), CNR, Research Unit of Brescia, 25123 Brescia, Italy; $\odot$ orcid.org/00000002-0011-5946; Email: giovanna.longhi@unibs.it

\section{Authors}

Simone Ghidinelli - Department of Molecular and Translational Medicine, University of Brescia, 25123 Brescia, Italy; ๑ orcid.org/0000-0001-5468-7715

Sergio Abbate - Department of Molecular and Translational Medicine, University of Brescia, 25123 Brescia, Italy; National Institute of Optics (INO), CNR, Research Unit of Brescia, 25123 Brescia, Italy; ๑ orcid.org/0000-0001-93591214

Giuseppe Mazzeo - Department of Molecular and Translational Medicine, University of Brescia, 25123 Brescia, Italy; $\odot$ orcid.org/0000-0002-3819-6438

Roberto Paolesse - Department of Chemical Science and Technologies, University of Rome Tor Vergata, 00133 Rome, Italy; ๑ orcid.org/0000-0002-2380-1404

Complete contact information is available at: https://pubs.acs.org/10.1021/acsomega.1c04028

\section{Notes}

The authors declare no competing financial interest.

\section{ACKNOWLEDGMENTS}

This study was carried out with the support of resources of Big\&Open Data Innovation Laboratory (BODaI-Lab), University of Brescia, granted by Fondazione Cariplo and Regione 
Lombardia and of Computing Center CINECA (Bologna), Italy. Funding from the Italian Ministry of Education, University and Research (MIUR) through the PRIN 2017 program (Project 2017A4XRCA_003 "Physico-chemical Heuristic Approaches: Nanoscale Theory of Molecular Spectroscopy [PHANTOMS]") and University of Brescia Research Fund (ex 60\%) is acknowledged. We thank $\mathrm{PhD}$ School: "Molecular Genetics, Biotechnologies and Experimental Medicine", University of Brescia for covering publication costs.

\section{REFERENCES}

(1) Johnson, A. W.; Kay, I. T. Corroles. Part I. Synthesis. J. Chem. Soc. 1965, 1620-1629.

(2) Paolesse, R. Syntheses of Corroles. In The Porphyrin Handbook; Kadish, K. M.; Smith, K. M.; Guilard, R., Eds.; Academic Press: New York, 2000; Vol. 2, Chapter 11, pp 201-232.

(3) Ghosh, A. Electronic Structure of Corrole Derivatives: Insights from Molecular Structures, Spectroscopy, Electrochemistry, and Quantum Chemical Calculations. Chem. Rev. 2017, 117, 3798-3881.

(4) Nardis, S.; Mandoj, F.; Stefanelli, M.; Paolesse, R. Metal complexes of corrole. Coord. Chem. Rev. 2019, 388, 360-405.

(5) Ganguly, S.; Ghosh, A. Seven Clues to Ligand Noninnocence: The Metallocorrole Paradigm. Acc. Chem. Res. 2019, 52, 2003-2014.

(6) Paolesse, R.; Nardis, S.; Monti, D.; Stefanelli, M.; Di Natale, C. Porphyrinoids for Chemical Sensor Applications. Chem. Rev. 2017, 117, 2517-2583.

(7) Walker, D.; Chappel, S.; Mahammed, A.; Brunschwig, B. S.; Winkler, J. R.; Gray, H. B.; Zaban, A.; Gross, Z. Corrole-sensitized $\mathrm{TiO}_{2}$ solar cells. J. Porphyrins Phthalocyanines 2006, 10, 1259-1262. (8) Higashino, T.; Kurumisawa, Y.; Alemayehu, A. B.; Einrem, R. F.; Sahu, D.; Packwood, D.; Kato, K.; Yamakata, A.; Ghosh, A.; Imahori, H. Heavy Metal Effects on the Photovoltaic Properties of Metallocorroles in Dye-Sensitized Solar Cells. ACS Appl. Energy Mater. 2020, 3, 12460-12467.

(9) Teo, R. D.; Hwang, J. Y.; Termini, J.; Gross, Z.; Gray, H. B. Fighting Cancer with Corroles. Chem. Rev. 2017, 117, 2711-2729.

(10) Arambula, J. F.; Sessler, J. L. Porphyrinoids Drug Conjugates. Chem 2020, 6, 1634-1651.

(11) Zhang, W.; Lai, W.; Cao, R. Energy-Related Small Molecule Activation Reactions: Oxygen Reduction and Hydrogen and Oxygen Evolution Reactions Catalyzed by Porphyrin- and Corrole-Based Systems. Chem. Rev. 2017, 117, 3717-3797.

(12) Rana, A.; Lee, Y. M.; Li, X.; Cao, R.; Fukuzumi, S.; Nam, W. Highly Efficient Catalytic Two-Electron Two-Proton Reduction of Dioxygen to Hydrogen Peroxide with a Cobalt Corrole Complex. ACS Catal. 2021, 11, 3073-3083.

(13) Liu, X.; Mahammed, A.; Tripathy, U.; Gross, Z.; Steer, R. P. Photophysics of Soret-excited tetrapyrroles in solution. III. Porphyrin analogues: Aluminum and gallium corroles. Chem. Phys. Lett. 2008, $459,113-118$.

(14) Kowalska, D.; Liu, X.; Tripathy, U.; Mahammed, A.; Gross, Z.; Hirayama, S.; Steer, R. P. Ground- and Excited-State Dynamics of Aluminum and Gallium Corroles. Inorg. Chem. 2009, 48, 2670-2676.

(15) Bendix, J.; Dmochowski, I. J.; Gray, H. B.; Mahammed, A.; Simkhovich, L.; Gross, Z. Structural, Electrochemical, and Photophysical Properties of Gallium(III) 5,10,15-Tris(pentafluorophenyl)corrole. Angew. Chem., Int. Ed. 2000, 39, 4048-4051.

(16) Savoldelli, A.; Nardis, S.; Genovese, D.; Prodi, L.; Fronczek, F. R.; Smith, K. M.; Paolesse, R. Moving corrole towards a red-record: synthesis of $\beta$-acrolein $\mathrm{Ga}$ and $\mathrm{Cu}$ corroles using the Vilsmeier reaction. New J. Chem. 2018, 42, 8200-8206.

(17) Ueta, K.; Fukuda, M.; Kim, G.; Shimizu, S.; Tanaka, T.; Kim, D.; Osuka, A. The First Silicon(IV) Corrole Complexes: Synthesis, Structures, Properties, and Formation of a $\mu$-Oxo Dimer. Chem. Eur. J. 2018, 24, 7637-7646.

(18) Pomarico, G.; Monti, D.; Bischetti, M.; Savoldelli, A.; Fronczek, F. R.; Smith, K. M.; Genovese, D.; Prodi, L.; Paolesse, R. Silicon(IV) Corroles. Chem. - Eur. J. 2018, 24, 8438-8446.
(19) Nardis, S.; Mandoj, F.; Paolesse, R.; Fronczek, F. R.; Smith, K. M.; Prodi, L.; Montalti, M.; Battistini, G. Synthesis and Functionalization of Germanium Triphenylcorrolate: the First Example of a Partially Brominated Corroles. Eur. J. Inorg. Chem. 2007, 2007, 23452352.

(20) Ghosh, A.; Ravikanth, M. Synthesis, Structure, Spectroscopic, and Electrochemical Properties of Highly Fluorescent Phosphorus(V)-meso-Triarylcorroles. Chem. - Eur. J. 2012, 18, 6386-6396.

(21) Liang, X.; Mack, J.; Zheng, L. -M.; Shen, Z.; Kobayashi, N. Phosphorus(V)-Corrole: Synthesis, Spectroscopic Properties, Theoretical Calculations, and Potential Utility for in Vivo Applications in Living Cells. Inorg. Chem. 2014, 53, 2797-2802.

(22) Vestfrid, J.; Kothari, R.; Kostenko, A.; Goldberg, I.; Tumanskii, B.; Gross, Z. Intriguing Physical and Chemical Properties of Phosphorus Corroles. Inorg. Chem. 2016, 55, 6061-6067.

(23) Naitana, M. L.; Nardis, S.; Pomarico, G.; Raggio, M.; Caroleo, F.; Cicero, D. O.; Lentini, S.; Prodi, L.; Genovese, D.; Mitta, S.; Sgarlata, A.; Fanfoni, M.; Persichetti, L.; Paolesse, R. A Highly Emissive Water-Soluble Phosphorus Corrole. Chem. - Eur. J. 2017, 23, 905-916.

(24) Gouterman, M.; Wagnière, G. H.; Snyder, L. C. Spectra of Porphyrins: Part II. Four Orbital Model. J. Mol. Spectrosc. 1963, 11, $108-115$.

(25) Gouterman, M. In The Porphyrins; Dolphin, D., Ed.; Academic Press: New York, 1978; Vol. III, pp 1-165.

(26) D’Andrea, A.; Pomarico, G.; Nardis, S.; Paolesse, R.; Di Natale, C.; Lvova, L. Chemical traffic Light: A Self-Calibrating Naked-Eye Sensor for Fluoride. J. Porphyrins Phthalocyanines 2019, 23, 117-124.

(27) Fawell, J.; Bailey, K.; Chilton, J.; Dahi, E.; Fewtrell, L.; Magara, Y. Fluoride in Drinking Water.; World Health Organization: London, 2006.

(28) Bassin, E. B.; Wypij, D.; Davis, R. B.; Mittleman, M. A. Agespecific Fluoride Exposure in Drinking Water and Osteosarcoma (United States). Cancer Causes Control 2006, 17, 421-428.

(29) Buckingham, A. D.; Stephens, P. J. Magnetic Optical Activity. Annu. Rev. Phys. Chem. 1966, 17, 399-432.

(30) Seth, M.; Autschbach, J.; Ziegler, T. Calculation of the B Term of Magnetic Circular Dichroism. A Time-Dependent Density Functional Theory Approach. J. Chem. Theory Comput. 2007, 3, 434-447.

(31) Ganyushin, D.; Neese, F. First-Principles Calculations of Magnetic Circular Dichroism Spectra. J. Chem. Phys. 2008, 128, No. 114117.

(32) Kjærgaard, T.; Kristensen, K.; Kauczor, J.; Jørgensen, P.; Coriani, S.; Thorvaldsen, A. J. Comparison of standard and damped response formulations of magnetic circular dichroism. J. Chem. Phys. 2011, 135, No. 024112.

(33) Stěpánek, P.; Boứ, P. Computation of magnetic circular dichroism by sum over states summations. J. Comput. Chem. 2013, 34, $1531-1539$.

(34) Ziegler, C. J.; Sabin, J. R.; Geier, G. R., III; Nemykin, V. N. The First TDDFT and MCD studies of free base triarylcorroles: A closer look into solvent-dependent UV-visible absorption. Chem. Commun. 2012, 48, 4743-4745.

(35) Kobayashi, N.; Nakai, K. Applications of magnetic circular dichroism spectroscopy to porphyrins and phthalocyanines. Chem. Commun. 2007, 45, 4077-4092.

(36) Mack, J.; Stillman, M. J.; Kobayashi, N. Application of MCD spectroscopy to porphyrinoids. Coord. Chem. Rev. 2007, 251, 429453.

(37) Ghidinelli, S.; Abbate, S.; Santoro, E.; Belviso, S.; Longhi, G. Characterization of "Free Base" and Metal Complex Thioalkyl Porphyrazines by Magnetic Circular Dichroism and TDDFT Calculations. J. Phys. Chem. B 2021, 125, 264-280.

(38) Ghidinelli, S.; Abbate, S.; Mazzeo, G.; Paoloni, L.; Viola, E.; Ercolani, C.; Donzello, M. P.; Longhi, G. Characterization of tetrakis(thiadiazole)porphyrazine metal complexes by magnetic circular dichroism and magnetic circularly polarized luminescence. Chirality 2020, 32, 808-816. 
(39) Morita, M.; Ozawa, T.; Tsubomura, T. Magnetic circularly polarized luminescence and electronic structures of europium(III) complexes of $2,2^{\prime}$-bipyridine-1, $1^{\prime}$-dioxide and other ligand. J. Lumin. 1992, 53, 495-498.

(40) Wu, T.; Kapitán, J.; Andrushchenko, V.; Bouř, P. Identification of Lanthanide(III) Luminophores in Magnetic Circularly Polarized Luminescence Using Raman Optical Activity Instrumentation. Anal. Chem. 2017, 89, 5043-5049.

(41) Foster, D. R.; Richardson, F. S. Magnetic circularly polarized luminescence of 9-coordinate europium(III) complexes in aqueous solution. Inorg. Chem. 1983, 22, 3996-4002.

(42) Gasyna, Z.; Metcalf, D. H.; Schatz, P. N.; McConnell, C. L.; Williamson, B. E. Magnetooptical Spectroscopy of Zinc Octaethylporphyrin in an Argon Matrix. J. Phys. Chem. A 1995, 99, 5865-5872.

(43) Rhoda, H. M.; Crandall, L. A.; Geier, G. R., III; Ziegler, C. J.; Nemykin, V. N. Combined MCD/DFT/TDDFT Study of the Electronic Structure of Axially Pyridine Coordinated Metallocorroles. Inorg. Chem. 2015, 54, 4652-4662.

(44) Tiedemann, M. T.; Stillman, M. J. Application of magnetic circular dichroism spectroscopy to porphyrins, phthalocyanines and hemes. J. Porphyrins Phthalocyanines 2011, 15, 1134-1149.

(45) Ghosh, A.; Lee, W. -Z.; Ravikanth, M. Synthesis, Structure and Properties of a Five-Coordinated Oxophosphorus(V) meso-Triarylcorroles. Eur. J. Inorg. Chem. 2012, 2012, 4231-4239.

(46) Chen, Q. -C.; Xiao, Z. -Y.; Fite, S.; Mizrahi, A.; Fridman, N.; Zhan, X.; Keisar, O.; Cohen, Y.; Gross, Z. Tuning Chemical and Physical Properties of Phosphorus Corroles for Advanced Applications. Chem. - Eur. J. 2019, 25, 11383-11388.

(47) Jaworska, E.; Caroleo, F.; Di Natale, C.; Maksymiuk, K.; Paolesse, R.; Michalska, A. Si-corrole-based fluoride fluorometric turn-on sensor. J. Porphyrins Phthalocyanines 2020, 24, 929-937.

(48) Laurent, A. D.; Jacquemin, D. TD-DFT benchmarks: A review. Int. J. Quantum Chem. 2013, 113, 2019-2039.

(49) Beenken, W. J. D.; Presselt, M.; Ngo, T. H.; Dehaen, W.; Maes, W.; Kruk, M. Molecular Structures and Absorption Spectra Assignment of Corrole NH Tautomers. J. Phys. Chem. A 2014, 118, 862871.

(50) Cortina, H.; Senent, M. L.; Smeyers, Y. G. Ab Initio Comparative Study of the Structure and Properties of $\mathrm{H}_{2}$-Porphin and $\mathrm{H}_{2}-\mathrm{Phthalocyanine.} \mathrm{The} \mathrm{Electronic} \mathrm{Absorption} \mathrm{Spectra.} \mathrm{J.} \mathrm{Phys.}$ Chem. A 2003, 107, 8968-8974.

(51) Martynov, A. G.; Mack, J.; May, A. K.; Nyokong, T.; Gorbunova, Y. G.; Tsivadze, A. Y. Methodological Survey of Simplified TD-DFT Methods for Fast and Accurate Interpretation of UV-Vis-NIR Spectra of Phthalocyanines. ACS Omega 2019, 4, $7265-7284$.

(52) Michl, J. Magnetic circular dichroism of cyclic.pi-electron systems. 1. Algebraic solution of the perimeter model for the A and B terms of high-symmetry systems with a $(4 \mathrm{~N}+2)$-electron [n] annulene perimeter. J. Am. Chem. Soc. 1978, 100, 6801-6811.

(53) Michl, J. Magnetic circular dichroism of cyclic.pi.-electron systems. 2. Algebraic solution of the perimeter model for the B terms of systems with a $(4 \mathrm{~N}+2)$-electron [n]annulene perimeter. J. Am. Chem. Soc. 1978, 100, 6812-6818.

(54) Waluk, J.; Michl, J. Perimeter model and magnetic circular dichroism of porphyrin analogs. J. Org. Chem. 1991, 56, 2729-2735.

(55) Kaito, A.; Nozawa, T.; Yamamoto, T.; Hatano, M.; Orii, Y. LCAO MO SCF $\pi$-Electron Calculations on the Magnetic Circular Dichroism of Porphin, Protoporphyrin, and Porphyrin a. Chem. Phys. Lett. 1977, 52, 154-160.

(56) Piepho, S. B.; Schatz, P. N. Group Theory in Spectroscopy with Applications to Magnetic Circular Dichroism; John Wiley \& Sons: New York, 1983.

(57) Thomas, K. E.; Alemayehu, A. B.; Conradie, J.; Beavers, C. M.; Ghosh, A. The Structural Chemistry of Metallocorroles: Combined Xray Crystallography and Quantum Chemistry Studies Afford Unique Insights. Acc. Chem. Res. 2012, 45, 1203-1214.
(58) Kruk, M. M.; Klenitsky, D. V.; Maes, W. Molecular Structure and Conformation of Free Base Corroles. Macroheterocycles 2019, 12, $58-67$.

(59) Riehl, J. P.; Richardson, F. S. Theory of magnetic circularly polarized emission. J. Chem. Phys. 1977, 66, 1988-1998.

(60) Pritchard, B.; Autschbach, J. Calculation of the Vibrationally Resolved, Circularly Polarized Luminescence of $d$-Camphorquinone and $(S, S)$-trans- $\beta$-Hydrindanone. ChemPhysChem 2010, 11, 24092415.

(61) Pecul, M.; Ruud, K. The optical activity of $\beta, \gamma$-enones in ground and excited states using circular dichroism and circularly polarized luminescence. Phys. Chem. Chem. Phys. 2011, 13, 643-650.

(62) Longhi, G.; Castiglioni, E.; Abbate, S.; Lebon, F.; Lightner, D. A. Experimental and Calculated CPL Spectra and Related Spectroscopic Data of Camphor and Other Simple Chiral Bicyclic Ketones. Chirality 2013, 25, 589-599.

(63) Paolesse, R.; Boschi, T.; Licoccia, S.; Khoury, R. G.; Smith, K. M. Phosphorus complex of corrole. Chem. Commun. 1998, 11191120.

(64) Castiglioni, E.; Abbate, S.; Longhi, G. Revisiting with Updated Hardware an Old Spectroscopic Technique: Circularly Polarized Luminescence. Appl. Spectrosc. 2010, 64, 1416-1419.

(65) Longhi, G.; Castiglioni, E.; Koshoubu, J.; Mazzeo, G.; Abbate, S. Circularly Polarized Luminescence: A Review of Experimental and Theoretical Aspects. Chirality 2016, 28, 696-707.

(66) Frisch, M. J.; Trucks, G. W.; Schlegel, H. B.; Scuseria, G. E.; Robb, M. A.; Cheeseman, J. R.; Scalmani, G.; Barone, V.; Petersson, G. A.; Nakatsuji, H.; Li, X.; Caricato, M.; Marenich, A. V.; Bloino, J.; Janesko, B. G.; Gomperts, R.; Mennucci, B.; Hratchian, H. P.; Ortiz, J. V.; Izmaylov, A. F.; Sonnenberg, J. L.; Williams-Young, D.; Ding, F.; Lipparini, F.; Egidi, F.; Goings, J.; Peng, B.; Petrone, A.; Henderson, T.; Ranasinghe, D.; Zakrzewski, V. G.; Gao, J.; Rega, N.; Zheng, G.; Liang, W.; Hada, M.; Ehara, M.; Toyota, K.; Fukuda, R.; Hasegawa, J.; Ishida, M.; Nakajima, T.; Honda, Y.; Kitao, O.; Nakai, H.; Vreven, T.; Throssell, K.; Montgomery, J. A., Jr.; Peralta, J. E.; Ogliaro, F.; Bearpark, M. J.; Heyd, J. J.; Brothers, E. N.; Kudin, K. N.; Staroverov, V. N.; Keith, T. A.; Kobayashi, R.; Normand, J.; Raghavachari, K.; Rendell, A. P.; Burant, J. C.; Iyengar, S. S.; Tomasi, J.; Cossi, M.; Millam, J. M.; Klene, M.; Adamo, C.; Cammi, R.; Ochterski, J. W.; Martin, R. L.; Morokuma, K.; Farkas, O.; Foresman, J. B.; Fox, D. J. Gaussian 16, revision C.01, Gaussian, Inc.: Wallingford, CT, 2016.

(67) Grimme, S.; Ehrlich, J. A. S.; Krieg, H. A consistent and accurate $a b$ initio parametrization of density functional dispersion correction (DFT-D) for the 94 Elements H-Pu. J. Chem. Phys. 2010, 132, No. 154104.

(68) Solheim, H.; Ruud, K.; Coriani, S.; Norman, P. The A and B Terms of Magnetic Circular Dichroism Revisited. J. Phys. Chem. A 2008, 112, 9615-9618.

(69) Aidas, K.; Angeli, C.; Bak, K. L.; Bakken, V.; Bast, R.; Boman, L.; Christiansen, O.; Cimiraglia, R.; Coriani, S.; Dahle, P.; Dalskov, E. K.; Ekström, U.; Enevoldsen, T.; Eriksen, J. J.; Ettenhuber, P.; Fernández, B.; Ferrighi, L.; Fliegl, H.; Frediani, L.; Hald, K.; Halkier, A.; Hättig, C.; Heiberg, H.; Helgaker, T.; Hennum, A. C.; Hettema, H.; Hjertenæs, E.; Høst, S.; Høyvik, I. -M.; Iozzi, M. F.; Jansík, B.; Jensen, A. H. J.; Jonsson, D.; Jørgensen, P.; Kauczor, J.; Kirpekar, S.; Kjærgaard, T.; Klopper, W.; Knecht, S.; Kobayashi, R.; Koch, H.; Kongsted, J.; Krapp, A.; Kristensen, K.; Ligabue, A.; Lutnæs, O. B.; Melo, J. I.; Mikkelsen, K. V.; Myhre, R. H.; Neiss, C.; Nielsen, C. B.; Norman, P.; Olsen, J.; Olsen, J. M. H.; Osted, A.; Packer, M. J.; Pawlowski, F.; Pedersen, T. B.; Provasi, P. F.; Reine, S.; Rinkevicius, Z.; Ruden, T. A.; Ruud, K.; Rybkin, V. V.; Sałek, P.; Samson, C. C. M.; Sánchez de Merás, A.; Saue, T.; Sauer, S. P. A.; Schimmelpfennig, B.; Sneskov, K.; Steindal, A. H.; Sylvester-Hvid, K. O.; Taylor, P. R.; Teale, A. M.; Tellgren, E. I.; Tew, D. P.; Thorvaldsen, A. J.; Thøgersen, L.; Vahtras, O.; Watson, M. A.; Wilson, D. J. D.; Ziolkowski, M.; Ågren, H. The Dalton quantum chemistry program system. WIREs Comput. Mol. Sci. 2014, 4, 269-284.

(70) Dalton, A Molecular Electronic Structure Program, Release v2019.alpha (2019), see: https://daltonprogram.org. 
(71) Schaftenaar, G.; Noordik, J. H. Molden: a pre- and postprocessing program for molecular and electronic structures. J. Comput.-Aided Mol. Des. 2000, 14, 123-134. 